Atmos. Chem. Phys., 13, 10907-10917, 2013

www.atmos-chem-phys.net/13/10907/2013/

doi:10.5194/acp-13-10907-2013

(c) Author(s) 2013. CC Attribution 3.0 License.

\title{
A critical assessment of high-resolution aerosol optical depth retrievals for fine particulate matter predictions
}

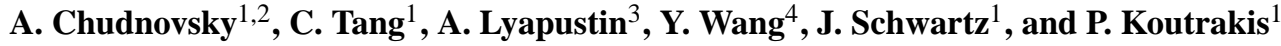 \\ ${ }^{1}$ Department of Environmental Health, Harvard School of Public Health, Boston, MA, USA \\ ${ }^{2}$ Department of Geography and Human Environment, Tel Aviv University, Tel Aviv, Israel \\ ${ }^{3}$ NASA Goddard Space Flight Center, Greenbelt, MD, USA \\ ${ }^{4}$ Joint Center for Earth Systems Technology, University of Maryland Baltimore County, Baltimore, MD 21228, USA
}

Correspondence to: A. Chudnovsky (achudnov@hsph.harvard.edu)

Received: 21 April 2013 - Published in Atmos. Chem. Phys. Discuss.: 4 June 2013

Revised: 28 August 2013 - Accepted: 8 October 2013 - Published: 7 November 2013

\begin{abstract}
Recently, a new Multi-Angle Implementation of Atmospheric Correction (MAIAC) algorithm was developed for the MODerate Resolution Imaging Spectroradiometer (MODIS), which provides aerosol optical depth (AOD) at $1 \mathrm{~km}$ resolution. The relationship between MAIAC AOD and $\mathrm{PM}_{2.5}$ as measured by 84 EPA ground monitoring stations in the entire New England and the Harvard super site during 2002-2008 was investigated and also compared to the AOD-PM 2.5 relationship using conventional MODIS $10 \mathrm{~km}$ AOD retrieval from Aqua platform (MYD04) for the same days and locations. The correlations for MYD04 and for MAIAC are $r=0.62$ and 0.65 , respectively, suggesting that AOD is a reasonable proxy for $\mathrm{PM}_{2.5}$ ground concentrations. The slightly higher correlation coefficient $(r)$ for MAIAC can be related to its finer resolution resulting in better correspondence between AOD and EPA monitoring sites. Regardless of resolution, AOD-PM 2.5 relationship varies daily, and under certain conditions it can be negative (due to several factors such as an EPA site location (proximity to road) and the lack of information about the aerosol vertical profile). By investigating MAIAC AOD data, we found a substantial increase, by $50-70 \%$ in the number of collocated AOD-PM 2.5 pairs, as compared to MYD04, suggesting that MAIAC AOD data are more capable in capturing spatial patterns of $\mathrm{PM}_{2.5}$. Importantly, the performance of MAIAC AOD retrievals is slightly degraded but remains reliable under partly cloudy conditions when MYD04 data are not available, and it can be used to increase significantly the number of days for $\mathrm{PM}_{2.5}$ spatial pattern prediction based on satellite observations.
\end{abstract}

\section{Introduction}

Exposure to particulate matter (PM) with aerodynamic diameter $\leq 2.5 \mu \mathrm{m}\left(\mathrm{PM}_{2.5}\right)$ causes a variety of adverse health effects in humans. Thus it is important to assess accurately the $\mathrm{PM}_{2.5}$ exposures that can be used in epidemiological studies (Zhu et al., 2006; Bell et al., 2011; Logue et al., 2010).

Routine measurements of ground-level $\mathrm{PM}_{2.5}$ concentrations by air quality monitoring networks are of great importance in assessing exposures, but their spatial coverage is limited. The satellite remote sensing can be an important tool to complement the ground-level measurements. The relevant satellite-derived parameter is the aerosol optical depth (AOD), which quantifies the extinction of solar radiation at a given wavelength due to presence of aerosols in an atmospheric column. Because the satellite-derived AOD is a measure of light attenuation in the column that is affected by ambient conditions (e.g., variable humidity, vertical profile, chemical composition etc.), while $\mathrm{PM}_{2.5}$ mass is a measure of dry particles near the surface, these two parameters are not expected to be strictly correlated.

Hoff and Christopher (2009) reviewed more than 30 papers that investigated the relationships between total-column AOD and surface $\mathrm{PM}_{2.5} / \mathrm{PM}_{10}$ measurements. Since 2010, the Scopus database, produced by Elsevier Science, has yielded about 40 additional publications related to ambient particulate matter concentrations $\left(\mathrm{PM}_{2.5}\right.$ and/or $\left.\mathrm{PM}_{10}\right)$ and air quality from satellite-based AOD. This growing body of work combines information from satellite sensors and models (van Donkelaar et al., 2010, 2013), introduces auxiliary 
information such as meteorological data (Pelletier et al., 2007; Emili et al., 2010; Wu et al., 2012; Kanabkaew, 2013) and boundary layer height (Engel-Cox et al., 2006; Tsai et al., 2011; Estellés et al., 2012), and also employs light detection and ranging (lidar) instruments to capture the vertical aerosol distribution at specific locations (Schaap et al., 2009; Barnaba et al., 2010). These recently developed approaches use various statistical methods, from linear regression models (Wang and Christopher, 2003; Tian and Chen, 2010) to more complex multiple regression and neural network techniques (Gupta and Christopher, 2009a, b), generalized additive mixed models (GAMs) (Liu et al., 2009; Paciorek et al., 2008; Paciorek and Liu, 2012), and mixed effects models (Lee et al., 2011; Chudnovsky et al., 2012).

The MODerate Resolution Imaging Spectroradiometer (MODIS) on board the Terra and Aqua satellites provides a daily global coverage, but the conventional resolution of its aerosol product $(10 \mathrm{~km})$ is often too coarse for suitable exposure estimates in urban areas. The widely anticipated $3 \mathrm{~km}$ MODIS AOD product is expected to be generated as a part of the Collection 6 reprocessing (Levy et al., 2013; Remer et al., 2013). Kumar et al. (2011) retrieved AOD at 2, 5 and $10 \mathrm{~km}$ spatial resolution using the standard MODIS darktarget aerosol retrieval algorithm (Levy et al., 2007). The authors found that the $2 \mathrm{~km}$ AOD was more promising for time and space resolved estimates of ambient PM than the $10 \mathrm{~km}$ AOD because of better location precision and the larger number of data points across geographic space and time. A recent assessment of the MODIS C6 $3 \mathrm{~km}$ product (Munchak et al., 2013) demonstrates better resolution of fine aerosol features than the $10 \mathrm{~km}$ product but is less reliable statistically, with about two-thirds of retrievals falling within the envelope of expected errors over urban surfaces. On the other hand, a new Multi-Angle Implementation of Atmospheric Correction (MAIAC) algorithm was developed for MODIS, which provides aerosol information at $1 \mathrm{~km}$ resolution (Lyapustin et al., 2011a, b). Emili et al. (2011) evaluated MAIAC AOD in the European Alpine region and demonstrated its enhanced capabilities compared to the standard MODIS AOD product. Chudnovsky et al. (2013) assessed the potential of the MAIAC AOD for examining the spatial patterns of $\mathrm{PM}_{2.5}$ in the Boston metropolitan area (intra-urban scale, $<10 \mathrm{~km}$ ) and parts of New England (regional scale). This study included 70 days during 2003 and was repeated for progressively degraded resolutions at 3,5 and $10 \mathrm{~km}$, obtained from the original $1 \mathrm{~km}$ AOD data by simple averaging. It was found that the correlation between $\mathrm{PM}_{2.5}$ and AOD decreased significantly as AOD resolution was degraded. However, a direct comparison between MAIAC $1 \mathrm{~km}$ AOD (fine) and the most validated MODIS $10 \mathrm{~km}$ AOD (coarse) retrieval to assess its potential in the future exposure assessments has been missing.

The current study assesses the quality of MAIAC $1 \mathrm{~km}$ AOD data by a comprehensive analysis of the relationship between $\mathrm{PM}_{2.5}$ and AOD. To augment previous studies,

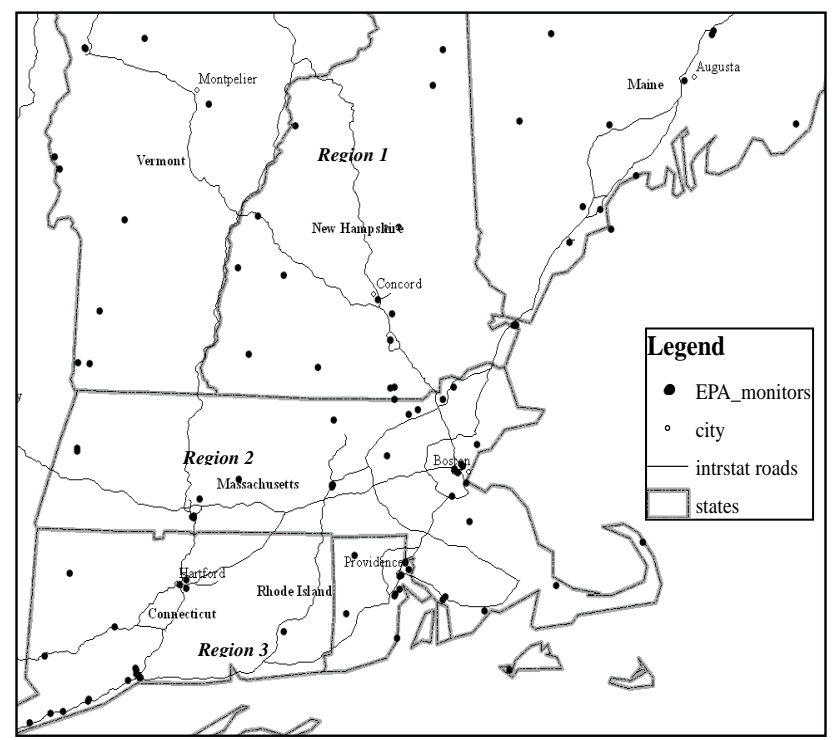

Fig. 1. Study area and EPA monitoring sites for New England used for comparison between MYD04 and MAIAC data.

we started with a direct comparison between MYD04 and MAIAC retrievals for days when both products were available. To this end, a multi-year analysis was conducted to study the relation of same-day/same-location AOD vs. $\mathrm{PM}_{2.5}$ (2002-2008) in New England. To further understand the sources of variability in the AOD-PM 2.5 relationship, we repeated the multi-year analysis breaking down AOD vs. $\mathrm{PM}_{2.5}$ regressions by geographic region, season (spring, summer, fall, winter) and by site location. Finally, we explored the quality of MAIAC retrieval on days when MYD04 was not available, by examining the $\mathrm{PM}_{2.5}-\mathrm{AOD}$ relationship on a daily basis.

\section{Material and methods}

\subsection{Ground-level $\mathbf{P M}_{2.5}$ data}

Twenty-four-hour $\mathrm{PM}_{2.5}$ concentrations were measured at 84 US Environmental Protection Agency (EPA) $\mathrm{PM}_{2.5}$ monitoring sites during 2002-2008 (Fig. 1). These include 12 sites from Maine (ME), 15 sites from New Hampshire (NH), 10 sites from Vermont (VT), 22 sites from Massachusetts (MA), 16 sites from Connecticut (CT) and 9 sites from Rhode Island (RI). Sampling frequency differed by site and included samples collected every day, every third day, and every sixth day. Additionally, we used $24 \mathrm{~h} \mathrm{PM}_{2.5}$ concentrations from the Harvard School of Public Health (HSPH) supersite located near downtown Boston, MA. Data from this site have been used in a large number of epidemiological studies to assess the temporal variability of individual and population exposures in the region. 


\subsection{Satellite data}

A new algorithm MAIAC (Lyapustin et al., 2011a, b, 2012a) has been developed to process MODIS data. MAIAC retrieves aerosol parameters over land at $1 \mathrm{~km}$ resolution simultaneously with parameters of a surface bidirectional reflectance distribution function (BRDF). This is accomplished by using the time series of MODIS measurements and simultaneous processing of groups of pixels. The MAIAC algorithm ensures that the number of measurements exceeds the number of unknowns, a necessary condition for solving an inverse problem without empirical assumptions typically used by current operational algorithms. The MODIS time-series accumulation also provides multi-angle coverage for every surface grid cell, which is required for the BRDF retrievals from MODIS data. The aerosol parameters include optical depth, Ångström exponent from 0.47 and $0.67 \mu \mathrm{m}$, and aerosol type including background, smoke and dust models (Lyapustin et al., 2012b). The background models are specified regionally based on the climatology of the AErosol RObotic NETwork (AERONET) (Holben et al., 1998) sun-photometer data for relatively low AOD days $(<0.5)$. AERONET validation over the continental USA showed that MAIAC and MOD04 algorithms have a similar accuracy over dark and vegetated surfaces, but also showed that MAIAC generally improves accuracy over brighter surfaces, including most urban areas (Lyapustin et al., 2011b). The improved accuracy of MAIAC results from using the explicit surface characterization method in contrast to the empirical surface parameterization approach, which is utilized in the MOD04 algorithm. Further, MAIAC incorporates a cloud mask (CM) algorithm based on spatiotemporal analysis, which augments traditional pixel-level cloud detection techniques (Lyapustin et al., 2008). In this work, the residual contamination by clouds and cloud shadows was additionally reduced by discarding 2 pixels adjacent to detected clouds.

In addition to MAIAC data, we used daily MODIS Level 2 (MYD04) Collection 5.1 aerosol data from the Aqua platform that are produced at the spatial resolution of a $10 \mathrm{~km}^{2} \times 10 \mathrm{~km}^{2}$ (at nadir). The MYD04 aerosol products are derived operationally from spectral radiances measured by MODIS using seven spectral channels across the wavelength region between 470 and $2130 \mathrm{~nm}$ (Remer et al., 2005). Additional wavelengths in other parts of the spectrum are used to identify and mask out clouds, snow and suspended river sediments (Ackerman et al., 1998; Gao et al., 2002; Martins et al., 2002; Li et al., 2003). Aerosol properties within MYD04_L2 are derived by the inversion of MODISobserved reflectances using pre-computed radiative transfer look-up tables based on dynamical aerosol models (Kaufman et al., 1997; Remer et al., 2005). More details about the MODIS AOD retrieval are reported in Remer et al. (2005) and Levy et al. (2007, 2010).

We conducted a comparative analysis of AOD between MAIAC and the respective operational MYD04 products.
It is important to mention that MYD04 product is reported for the area of 20 by 20 pixels ( $500 \mathrm{~m}$ nadir resolution) in the swath format. This area corresponds to spatial resolution of $10 \mathrm{~km}^{2} \times 10 \mathrm{~km}^{2}$ at nadir. However, it grows with the scan angle reaching $\sim 20 \times 40 \mathrm{~km}^{2}$ at the edge of scan due to the respective growth of the MODIS pixel footprint by a factor of $\sim 2 \times 4$. On the contrary, MAIAC provides a uniform $1 \mathrm{~km}$ gridded resolution at selected projection regardless of the scan angle. This means that MAIAC product is under-sampled by a factor of 4 at nadir, considering maximal available spatial information from $500 \mathrm{~m}$ pixels, and is over-sampled by a factor of 2 at the edge of scan. In this regard, MYD04 data are always under-sampled by a factor of 400. In order to perform a direct MYD04-MAIAC comparison, the area of each MYD04 pixel was approximated by a polygon, and all MAIAC $1 \mathrm{~km}$ data fitting this area were averaged.

The MODIS operational approach ensures robust performance in conditions when aerosols are rather homogeneous at scales of tens of kilometers by selecting the "best" pixels for the retrievals, while MAIAC, by providing retrieval for every $1 \mathrm{~km}$ grid cell, may add noise due to remaining uncertainties in the surface reflectance, residual cloud/snow contamination, etc. On the other hand, MAIAC approach becomes indispensable in heterogeneous aerosol environments (e.g., with local sources such as fire smoke plumes or in urban/industrial areas).

\subsection{Data processing and analyses}

We investigated the associations between AOD and $\mathrm{PM}_{2.5}$ daily measurements at the sampling sites for the years 2002-2008. We first made a direct comparison between MYD04 and MAIAC retrievals, with a multi-year analysis of AOD vs. $\mathrm{PM}_{2.5}$ for the same days (2002-2008) and locations (85 EPA monitoring stations) in New England.

In addition, in our analyses we divided the entire New England area to three sub-regions: region 1 included ME, VT and $\mathrm{NH}$; region 2 included MA; and CT and RI formed region 3. Although there are some variations among the three regions in topography and climate conditions mostly via the typical north-south snow cover gradient in winter, the main difference appears at the level of urbanization and land use, affecting surface brightness and thus the quality of aerosol product. For instance, validation analysis of the MODIS $3 \mathrm{~km}$ product (Munchak et al., 2013, Fig. 9) showed a strong correlation between percent of retrievals with high error and percent of urban land cover. A similar investigation is ongoing for MAIAC. Of the three, region 1 is the least urbanized with a high fraction of forest cover, and region 2 is most urbanized. Thus, by dividing the study area to regions we can evaluate the role of environmental conditions (e.g., snow coverage) and different land use settings on the AOD$\mathrm{PM}_{2.5}$ relationship in the two algorithms. To this end, we performed AOD-PM ${ }_{2.5}$ regression analyses using the same data 

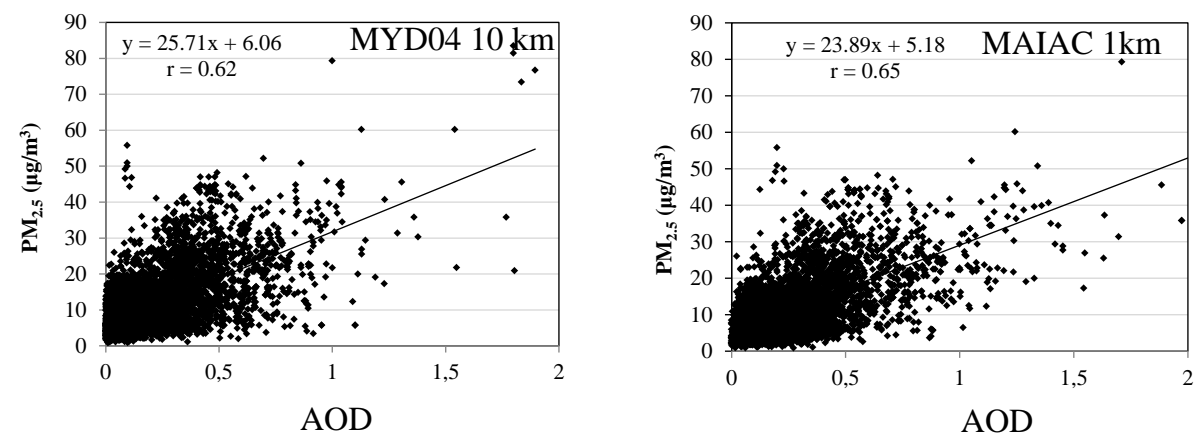

Fig. 2. AOD vs. $\mathrm{PM}_{2.5}$ relationships: comparison between $\mathrm{PM}_{2.5}$ and AOD for MODIS $10 \mathrm{~km}$ (MYD04, left) and MAIAC $1 \mathrm{~km}$ (right) for the same days and locations (2002-2008) in New England, 85 locations ( $N=6046$ observations).

within selected geographic regions $1-3$. Further, we calculated the AOD-PM 2.5 correlations by season (spring, summer, fall, and winter) for each of the three regions and conducted AOD-PM 2.5 regression analyses by site location.

According to our experience, MAIAC provides more AOD data collocated with PM ground monitors as compared to the standard MODIS aerosol product, and it captures a larger range of spatial PM variations by collocated AOD. Both qualities are important for $\mathrm{PM}_{2.5}$ model predictions based on satellite data. In this work, we quantified the differences for the two satellite AOD products for the New England region (85 EPA stations) during the period 4 July 2002-29 December 2008. Finally, the quality of MAIAC retrievals on days when MYD04 product was not available was examined on a daily basis using all available MAIAC data.

\section{Results and discussion}

\subsection{Direct comparison between MYD04 and MAIAC retrievals}

This section studies the subset of MYD04/MAIAC data for days when both products are available for a given EPA site. Since MAIAC generally provides more data, the limiting factor is availability of MYD04 product.

Figure 2 shows the direct comparison between $\mathrm{PM}_{2.5}$ and AOD from MYD04 and MAIAC for the same days and locations (2002-2008) in New England (85 locations, with at least 3 observations on a given day, 613 days). The AOD$\mathrm{PM}_{2.5}$ correlations for MYD04 and MAIAC are 0.62 and 0.65 , respectively. Table 1 shows the AOD-PM 2.5 correlations per geographic region, suggesting that $\mathrm{AOD}$ is a reasonable proxy for $\mathrm{PM}_{2.5}$ ground concentrations. As can be seen, the correlation varies by region and may decrease for larger geographic regions due to variation in local meteorological conditions, topography and aerosol profile, which are not accounted for in aerosol retrievals (Chudnovsky et al., 2013). We next explore sources of variation in the relationship.
Table 1. Direct comparison between coarse MYD04 AOD $10 \mathrm{~km}$ and fine-resolution MAIAC $1 \mathrm{~km}$ AOD for the same days and locations separately for each of geographic regions.

\begin{tabular}{lrr}
\hline Statistics & MYD04 & MAIAC \\
\hline Region 1 & & \\
\hline$N$ & 1722 & 1722 \\
Intercept & 5.48 & 4.16 \\
Slope & 25.21 & 22.27 \\
$p$ value & $<0.0001$ & $<0.0001$ \\
$r$ & 0.62 & 0.62 \\
\hline Region 2 & & \\
\hline$N$ & 1880 & 1880 \\
Intercept & 6.60 & 5.93 \\
Slope & 20.70 & 20.77 \\
$p$ value & $<0.0001$ & $<0.0001$ \\
$r$ & 0.56 & 0.61 \\
\hline Region 3 & & \\
\hline$N$ & 2444 & 2444 \\
Intercept & 6.14 & 5.47 \\
Slope & 29.70 & 27.15 \\
$p$ value & $<0.0001$ & $<0.0001$ \\
$r$ & 0.66 & 0.69 \\
\hline \multicolumn{2}{r}{}
\end{tabular}

The previous research has shown that the AOD-PM 2.5 relationship varies by both season and location (e.g., Zhang, et al., 2009). Table 2 presents a multi-year, seasonal (spring, summer, fall, winter) comparison between MYD04 and MAIAC. Although MAIAC shows intercepts that are lower than those for MYD04 for $7 \mathrm{yr}$ of measurements, slopes for both retrievals are similar. Both retrievals show similar correlations, and on average MAIAC provides slightly better results. The improvement is primarily in the more populated areas (regions 2 and 3). One can note the lack of data for region 1 and the negative slope for both products in region 2 for the winter season. The slopes have seasonal dependence 
Table 2. Seasonal comparison between coarse MYD04 AOD $10 \mathrm{~km}$ and fine-resolution MAIAC $1 \mathrm{~km}$ AOD for the same days and locations.

\begin{tabular}{|c|c|c|c|c|c|}
\hline \multicolumn{6}{|c|}{ Region 1} \\
\hline Data Source & Statistics & Summer & Fall & Winter & Spring \\
\hline \multirow{5}{*}{ MYD04 } & $N$ & 762 & 555 & 0 & 405 \\
\hline & Intercept & 6.33 & 5.72 & & 4.49 \\
\hline & Slope & 25.33 & 22.52 & & 20.82 \\
\hline & $p$ value & $<0.0001$ & $<0.0001$ & & $<0.0001$ \\
\hline & $r$ & 0.63 & 0.522 & & 0.501 \\
\hline \multirow{5}{*}{ MAIAC } & $N$ & 762 & 555 & 0 & 405 \\
\hline & Intercept & 5.13 & 4.55 & & 3.53 \\
\hline & Slope & 20.22 & 19.45 & & 18.22 \\
\hline & $p$ value & $<0.0001$ & $<0.0001$ & & \\
\hline & $r$ & 0.62 & 0.523 & & 0.492 \\
\hline \multicolumn{6}{|c|}{ Region 2} \\
\hline \multirow{5}{*}{ MYD04 } & $N$ & 688 & 651 & 28 & 513 \\
\hline & Intercept & 6.98 & 7.55 & 8.55 & 5.08 \\
\hline & Slope & 20.84 & 18.32 & -17.77 & 17.13 \\
\hline & $p$ value & $<0.0001$ & $<0.0001$ & 0.35 & $<0.0001$ \\
\hline & $r$ & 0.61 & 0.44 & -0.18 & 0.54 \\
\hline \multirow{5}{*}{ MAIAC } & $N$ & 688 & 651 & 28 & 513 \\
\hline & Intercept & 6.45 & 6.81 & 9.22 & 3.55 \\
\hline & Slope & 19.2 & 19.45 & -22.1 & 24.5 \\
\hline & $p$ value & $<0.0001$ & $<0.0001$ & 0.20 & $<0.0001$ \\
\hline & $r$ & 0.65 & 0.46 & -0.21 & 0.59 \\
\hline \multicolumn{6}{|c|}{ Region 3} \\
\hline \multirow{5}{*}{ MYD04 } & $N$ & 809 & 736 & 120 & 779 \\
\hline & Intercept & 6.31 & 7.31 & 8.38 & 4.33 \\
\hline & Slope & 30.09 & 28.6 & 30.47 & 27.21 \\
\hline & $p$ value & $<0.0001$ & $<0.0001$ & $<0.0001$ & $<0.0001$ \\
\hline & $r$ & 0.74 & 0.52 & 0.17 & 0.64 \\
\hline \multirow{5}{*}{ MAIAC } & $N$ & 809 & 736 & 120 & 779 \\
\hline & Intercept & 5.46 & 6.62 & 3.5 & 3.22 \\
\hline & Slope & 27.12 & 27.62 & 78.4 & 27.12 \\
\hline & $p$ value & $<0.0001$ & $<0.0001$ & $<0.0001$ & $<0.0001$ \\
\hline & $r$ & 0.78 & 0.52 & 0.45 & 0.63 \\
\hline
\end{tabular}

for both MYD04 and MAIAC and vary between 17 and $27 \mu \mathrm{g} \mathrm{m}^{-3}$ /AOD unit in spring, summer and fall.

Figure 3 (left) shows the average and standard deviation of the correlation coefficients between $\mathrm{PM}_{2.5}$ and AOD for all EPA sites for 2002-2008 (the same days were used for MAIAC and MYD04). In general, both retrievals provide similar and reasonable accuracy (e.g., the mean correlation coefficient for MAIAC is 0.66 vs. 0.62 for MYD04). Note also that the range of correlation coefficients across sites is tighter in MAIAC compared to MYD04, with about a $30 \%$ smaller interquartile range for MAIAC. The dashed boxes in Fig. 3 (right) highlight correlation coefficients across urban sites for two urban domains: New Haven and Boston (with five EPA sites for each). As can be seen, MAIAC shows similar correlations for New Haven but notably better correlations for Boston, where high resolution and improved performance of MAIAC over brighter urban areas (Lyapustin et al., 2011b) increase sensitivity of retrievals to the aerosol variability in

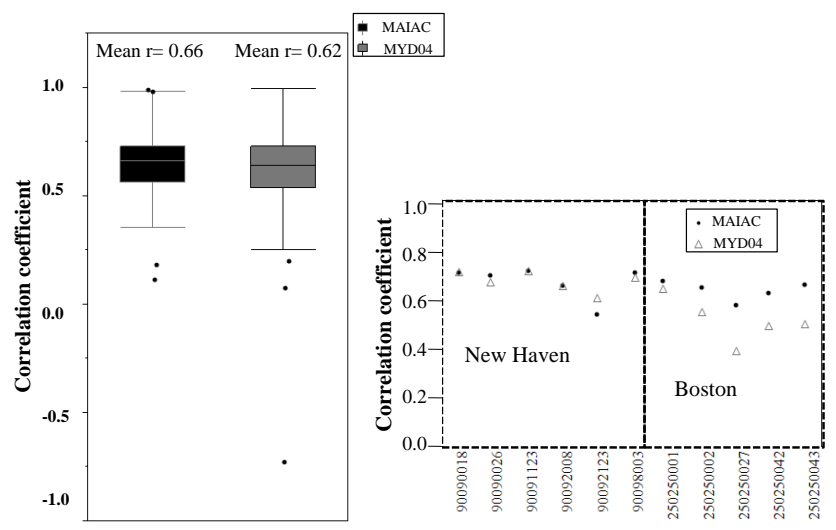

Fig. 3. Left: correlation coefficient between $\mathrm{PM}_{2.5}$ and $\mathrm{AOD}$ by EPA site location for 85 sites (years 2002-2008). Right: correlation coefficient between $\mathrm{PM}_{2.5}$ and AOD for two urban locations: New Haven area and Boston.
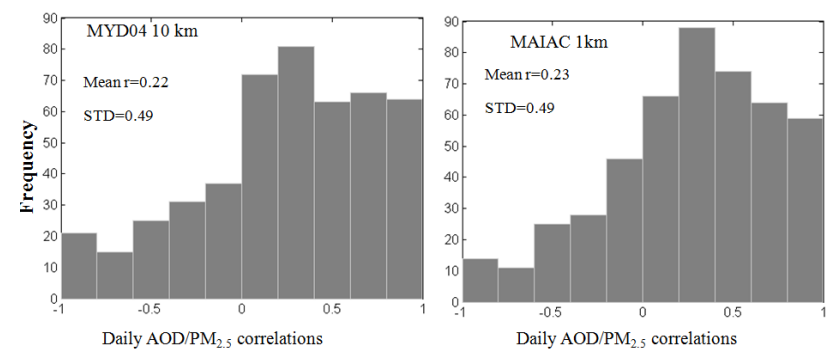

Fig. 4. Frequency distribution of daily AOD vs. $\mathrm{PM}_{2.5}$ correlations for MYD04 (left) and MAIAC (right).

the urban environment. Note that the range of correlations for both retrievals across the sites is substantial, which most likely reflects the local meteorological conditions and spatial homogeneity of $\mathrm{PM}_{2.5}$, namely how well the local $\mathrm{PM}_{2.5}$ measurement can be generalized to the larger footprint of the AOD pixel. This point is explored later in this paper.

While Fig. 3 shows the variation across monitoring sites of the site specific AOD-PM 2.5 correlations over time, Fig. 4 presents a histogram of spatial AOD- $\mathrm{PM}_{2.5}$ correlations across all sites computed for each day and accumulated for the period 2002-2008. Note that the same days/sites are used for both MAIAC and MYD04. As can be seen, the relationship changes substantially by date for both MYD04 and MAIAC. In general, both retrievals provide a similar accuracy.

\subsection{High-resolution retrievals: the entire data set}

The model-based exposure studies are sensitive to satellite constraints: given meteorological conditions, they require larger AOD coverage of a study region, which may translate into improved resolution of measured PM contrasts with AOD data and may improve PM prediction. Given the importance of this issue, this section uses the entire subset of 


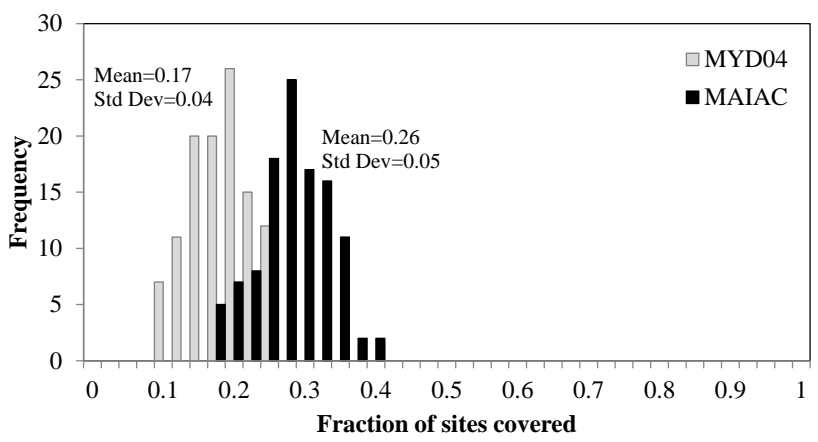

Fig. 5. Fraction of sites covered by MYD04 (grey bar) and MAIAC (black bar) calculated as number of observations with valid AOD retrievals divided by the total number of observations for each of EPA site $(N=85)$.

MAIAC data (regardless of MYD04 product availability) to quantify the observation coverage by the two algorithms.

Figure 5 shows the fraction of EPA sites covered by MYD04 and all available MAIAC data, computed as the number of observations with valid AOD retrievals divided by the total number of observations during 2002-2008 regardless of availability of $\mathrm{PM}_{2.5}$ data. As can be seen, on average MAIAC provides data for $26 \%$ of possible observations versus $17 \%$ for MYD04. To further this analysis, Fig. 6 presents the increase in the number of MAIAC AOD retrievals as compared to that of MYD04 for the region's EPA site locations. As can be seen, MAIAC provides a factor of 1.77 more observations than MYD04 for non-collocated pairs (regardless of available $\mathrm{PM}_{2.5}$ data, black bars) and a factor of 1.52 more observations when $\mathrm{PM}_{2.5}$ data were available (grey bars). The issue of PM data availability is rooted in the different sampling frequency among EPA sites mentioned in Sect. 2.1. For two urban sites located in greater Boston area, MAIAC gives a factor of 3-5 higher AOD coverage than MYD04 algorithm. In this case, the spatial resolution of the EPA ground monitoring network for closely located urban sites is matched or surpassed by the resolution of MAIAC AOD data, which is not the case for MYD04 (e.g., several sites covered by a single coarse AOD pixel). Two other sites with higher than average increase in observations (by factor of 3) are coastal sites located in MA (Aquinnah and Wellfleet). It should be mentioned that the new MODIS $3 \mathrm{~km}$ product is expected to improve coastal land coverage (Munchak et al., 2013). Figure 7 (left panel) re-plots the results of Fig. 6 in terms of frequency distribution of the number of collocated AOD-PM 2.5 pairs for the period of study 2002-2008. A site-level picture for 26 representative sites located in MA and CT is shown in Fig. 7 (right panel) with the MAIAC and MYD04 data displayed by black/grey bars, respectively. This graph confirms higher availability of the MAIAC AOD data for 25 of the selected 26 sites.

The increase in the number of MAIAC AOD retrievals can be linked to differences in the cloud mask and the conser-

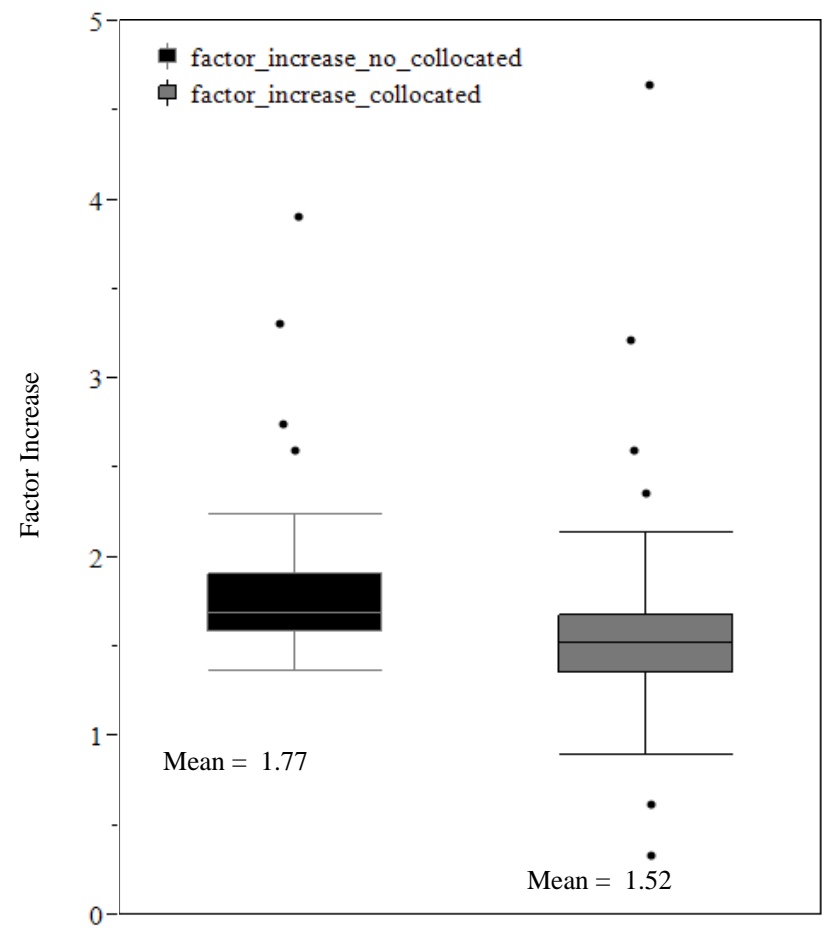

Fig. 6. Factor increase of coverage for MAIAC: non-collocated (black box) and collocated to $\mathrm{PM}_{2.5}$ observations (grey box).

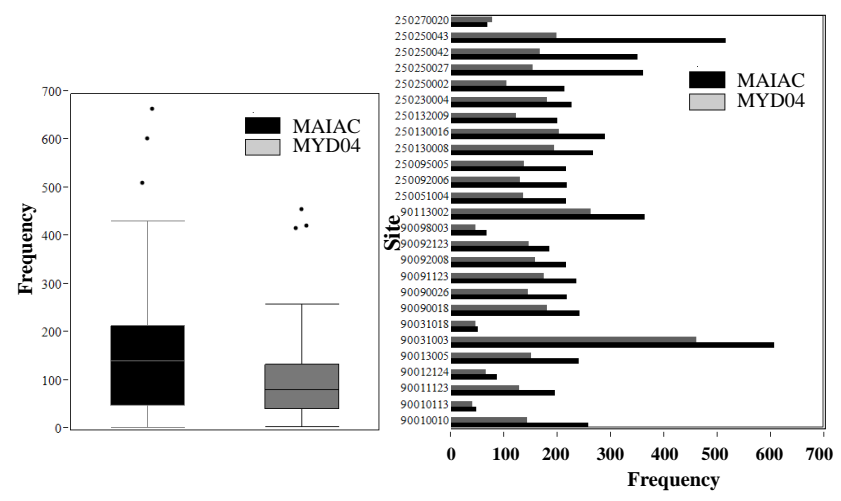

Fig. 7. Left: frequency distribution of the number of collocated AOD-PM 2.5 pairs at 85 EPA ground monitoring stations for MAIAC (black box) and for MYD04 (grey box) during the period 4 July 2002-29 December 2008 in New England. Right: the same as left but for representative EPA sites located in MA and CT.

vativeness of data filtering used to assure aerosol data quality in the MOD04 and MAIAC algorithms, as well as to the extended range of brighter surfaces in the MAIAC aerosol retrievals. For example, a recent comparison (Hilker et al., 2012) between MAIAC and MODIS operational cloud mask (MOD35), part of which is used in the MOD04 algorithm, showed that over the tropical Amazon Basin with very high average cloudiness (75-99\%), MAIAC provides on average between 20 and $80 \%$ more cloud-free data. 

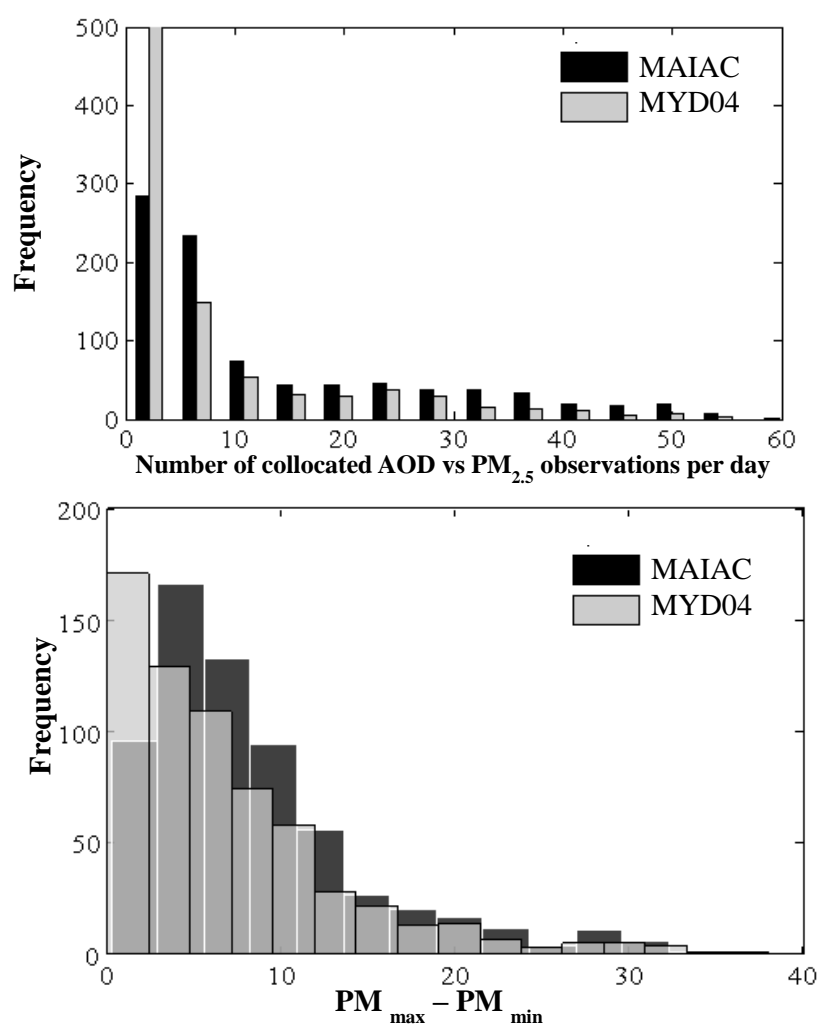

Fig. 8. Top: distribution of the number of available collocated AOD-PM 2.5 pairs per day based on $1 \mathrm{~km}$ MAIAC (black) and $10 \mathrm{~km}$ MYD04 (grey) retrievals. Bottom: distribution of the daily difference between maximal and minimal measured $\mathrm{PM}_{2.5}$ for collocated AOD pairs on a given day based on $1 \mathrm{~km}$ MAIAC (black) and $10 \mathrm{~km}$ MYD04 (grey) retrievals.

To conclude this part of our analysis, the upper panel of Fig. 8 shows the frequency distribution of the number of collocated AOD-PM 2.5 pairs per day. The mean number of pairs (or observed EPA sites from the total of 85) is 12.58 for MAIAC versus 9.88 for MYD04. The lower panel of Fig. 8 shows the distribution of the maximal daily PM contrast (daily difference between maximum and minimum measured $\mathrm{PM}_{2.5}$ concentrations) for collocated AOD-PM 2.5 pairs. One can see that with larger spatial coverage, MAIAC also captures more days with greater spatial variation in $\mathrm{PM}_{2.5}$ (in the range $5-30 \mu \mathrm{g} \mathrm{m}^{-3}$ ), which creates the potential for improving the AOD-PM correlation. On the contrary, the maximal frequency of $10 \mathrm{~km}$ MYD04 observations happens on days with lowest PM variability $\left(<5 \mu \mathrm{g} \mathrm{m}^{-3}\right)$ where the expected sensitivity of AOD for PM predictions is also low. Thus, while the coarse-resolution AOD can capture $\mathrm{PM}_{2.5}$ variability on certain days, the high resolution provides a higher number of AOD-PM $M_{2.5}$ pairs with expanded range of variability in $\mathrm{PM}_{2.5}$ concentrations on a given day.
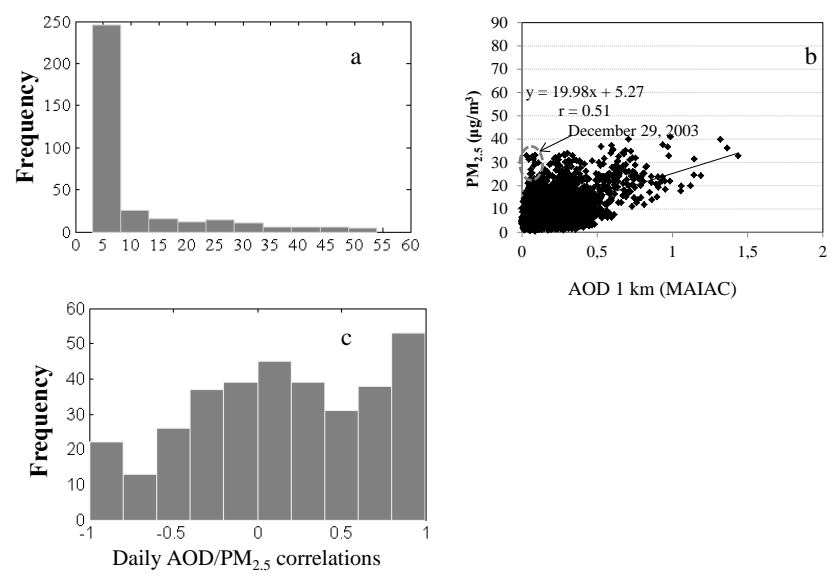

Fig. 9. MAIAC data quality on days when MYD04 was not available. (a) Number of collocated AOD-PM 2.5 pairs with at least 3 observations retrieved by MAIAC ( $N=344$ days). (b) MAIAC AOD$\mathrm{PM}_{2.5}$ relationship on days when MYD04 has no collocated observations; (c) frequency distribution of daily AOD vs. $\mathrm{PM}_{2.5}$ correlations.

\subsection{MAIAC data quality when MYD04 is not available}

Depending on regional meteorology, the mass concentrations and daily pattern of $\mathrm{PM}_{2.5}$ cannot be estimated from satellite observations on certain days due to high cloud cover (Christopher and Gupta, 2010). With the increased resolution, MAIAC provides more data in partly cloudy conditions. These data could become a more valuable source to model $\mathrm{PM}_{2.5}$ concentrations than statistically derived values, provided that the data quality is sufficient. Below, the quality of MAIAC retrievals is evaluated for partly cloudy conditions on days where MYD04 data are not reported.

Figure 9a shows the number of collocated AOD-PM 2.5 pairs with at least 3 MAIAC observations but less than two MYD04 collocated pairs ( $N=343$ days). The mean MAIAC retrieval rate for such days was 8 pairs. In other words, 343 days would be excluded from our analyses based on MYD04 data but included if MAIAC data were used. Figure $9 \mathrm{~b}$ shows the MAIAC AOD-PM 2.5 linear regression on days when the MYD04 product is unavailable. It shows a correlation of $r=0.51$, and slope and intercept statistics similar to those of Fig. 2. Note that excluding 29 December 2003 with snow on the ground would increase the $r$ value to 0.54 . Furthermore, the frequency distribution of the correlation coefficient (Fig. 9c) shows a pattern similar to the one previously observed in Fig. 4 for mostly clear days. These results suggest that additional data offered by high-resolution MAIAC retrievals are suitable for future modeling of $\mathrm{PM}_{2.5}$ both in clear and partly cloudy conditions.

Table 3 presents the seasonal statistics of correlation for MAIAC for days when MYD04 was unavailable. Similarly to Table 2, the correlations are different for three regions and are seasonally dependent. Note that the same data set was 
Table 3. Seasonal statistics of correlation between fine-resolution MAIAC $1 \mathrm{~km}$ AOD and $\mathrm{PM}_{2.5}$ for days that MYD04 was unavailable.

\begin{tabular}{|c|c|c|c|c|}
\hline \multicolumn{5}{|c|}{ Region 1} \\
\hline Statistics & Summer & Fall & Winter & Spring \\
\hline$N$ & 193 & 397 & 160 & 200 \\
\hline Intercept & 5.71 & 3.76 & 7.89 & 4.33 \\
\hline Slope & 16.79 & 19.22 & 1.3 & 5.50 \\
\hline$p$ value & $<0.0001$ & $<0.0001$ & 0.048 & $<0.0001$ \\
\hline$r$ & 0.583 & 0.415 & 0.031 & 0.26 \\
\hline \multicolumn{5}{|c|}{ Region 2} \\
\hline$N$ & 172 & 394 & 351 & 241 \\
\hline Intercept & 9.12 & 5.69 & 7.89 & 6.21 \\
\hline Slope & 15.40 & 17.65 & 7.66 & 6.27 \\
\hline$p$ value & $<0.0001$ & $<0.0001$ & 0.002 & $<0.0001$ \\
\hline$r$ & 0.63 & 0.35 & 0.17 & 0.22 \\
\hline \multicolumn{5}{|c|}{ Region 3} \\
\hline$N$ & 189 & 409 & 388 & 245 \\
\hline Intercept & 6.29 & 6.63 & 9.53 & 6.54 \\
\hline Slope & 23.92 & 11.92 & 4.33 & 8.86 \\
\hline$p$ value & $<0.0001$ & $<0.0001$ & 0.003 & $<0.0001$ \\
\hline$r$ & 0.70 & 0.26 & 0.09 & 0.31 \\
\hline
\end{tabular}

used to produce both Table 3 and Fig. $9 \mathrm{~b}$. The only difference is that Fig. 9b includes all points (e.g., all seasons and all locations), while Table 3 makes differentiation based on season and region. Comparing Table 2 (MYD04 data available) and Table 3 (MYD04 unavailable), several conclusions might be drawn: (1) similar and relatively high correlations for summer, spring and fall seasons suggest that MAIAC AOD on cloudy days may serve as a suitable proxy for modeling of $\mathrm{PM}_{2.5}$ ground concentrations; (2) there is a significant increase in the number of winter retrievals using MAIAC. Although the correlation is low ( $r$ ranges from 0.03 to 0.17 ), it might be improved by filtering possible noise from undetected clouds and snow. Specifically, AOD values might be discarded in the following conditions: (1) they were greater than 1.7 ; (2) pairs with low $\mathrm{PM}_{2.5}$ concentrations but high AOD values (e.g., $\mathrm{PM}_{2.5}$ concentration lower than $5 \mu \mathrm{g} \mathrm{m}^{-3}$ and AOD higher than 0.4); and (3) pairs with high $\mathrm{PM}_{2.5}$ concentrations but low AOD values (e.g., $\mathrm{PM}_{2.5}$ concentration higher than $25 \mu \mathrm{g} \mathrm{m}^{-3}$ and AOD lower than 0.1).

\subsection{Site location impact and seasonality in AOD-PM 2.5 relationship}

Generally, $\mathrm{PM}_{2.5}$ estimation based on satellite AOD on a given day is affected by the choice of which collocated EPA $\mathrm{PM}_{2.5}$ vs. AOD pair is used due to not only the site location (e.g., proximity to roads) but also due to errors in both $\mathrm{PM}_{2.5}$
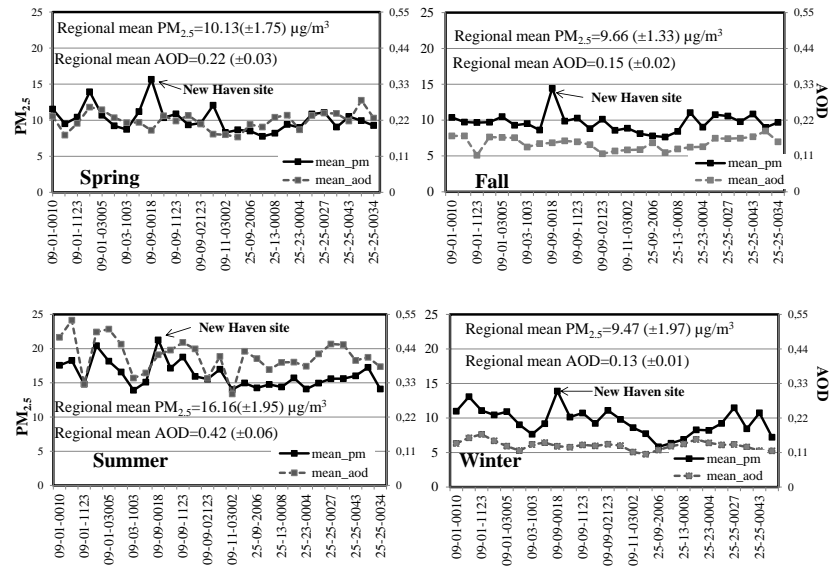

Fig. 10. Seasonal trend of average AOD and average $\mathrm{PM}_{2.5}$ for representative monitoring EPA sites located in MA and CT using all available MAIAC days.

concentrations and AOD values. This section studies the impact of site location on AOD vs. $\mathrm{PM}_{2.5}$ relationship.

Figure 10 shows the spatial (site) distribution of seasonally averaged AOD and $\mathrm{PM}_{2.5}$ values using all available days with MAIAC retrievals for selected urban sites in MA and CT chosen as an example to study the variability in a relationship. Except for the summer season, the average $\mathrm{PM}_{2.5}$ shows less seasonal variability than AOD. Specifically, the regional average of $\mathrm{PM}_{2.5}$ ranges from 9.47, 9.66 to $10.13 \mu \mathrm{g} \mathrm{m}^{-3}$ during winter, fall and spring, reaching its maximal value of $16.16 \mathrm{\mu g} \mathrm{m}^{-3}$ in summer, whereas average $\mathrm{AOD}_{0.47} \mathrm{val}-$ ues are $0.13,0.22,0.42$ and 0.15 during winter, spring, summer and fall. Much of the difference in variability between AOD and $\mathrm{PM}_{2.5}$ is due to the New Haven monitor, which reflects an extremely high traffic location. Given very similar $\mathrm{PM}_{2.5}$ in winter and spring, the almost a factor of 2 difference in AOD is mostly due to a difference in planetary boundary layer (PBL) height (or aerosol profile). These results suggest that control for traffic density and PBL height could improve the correlations between AOD and $\mathrm{PM}_{2.5}$.

In general, average AODs follow the general trend of average $\mathrm{PM}_{2.5}$ for most urban stations in MA and CT. However, several sites exhibit the opposite pattern: high AODlow $\mathrm{PM}_{2.5}$ or vice versa. This result is not surprising. In fact, the AOD value in a $1 \mathrm{~km}^{2} \times 1 \mathrm{~km}^{2}$ grid cell and or $10 \mathrm{~km}^{2} \times 10 \mathrm{~km}^{2}$ grid cell is an average optical depth in the given grid cell, which may correspond to an overall relatively low pollution area, whereas the $\mathrm{PM}_{2.5}$ measurement can reflect relatively higher pollution levels due to site proximity to localized pollution source. For instance, except in the summer season, $\mathrm{PM}_{2.5}$ concentrations measured at the New Haven, CT, site (site ID: 09-09-0018, highlighted by arrow at Fig. 10), located on a ramp to interstates I-95 and I-91 and also in the direct proximity to the port of New Haven (which is the busiest port between Boston and New York), 
were considerably higher than those observed at other sites, including the site located only $0.7 \mathrm{~km}$ away (site ID: 09-090026). Therefore, the relatively higher value of the mean $\mathrm{PM}_{2.5}$ concentrations for this site in comparison with the mean AOD can be explained by the fact that this site is not representative of the corresponding $1 \mathrm{~km}^{2} \times 1 \mathrm{~km}^{2}$ grid cell. The opposite condition can also occur: the AOD can indicate a relatively higher pollution level than the $\mathrm{PM}_{2.5}$ due to bias in the retrieval accuracy (e.g., over bright urban areas).

\section{Concluding remarks}

This paper analyzed the effect of spatial resolution of AOD product on the correlation between satellite-retrieved AOD and ground-based $\mathrm{PM}_{2.5}$ concentrations using $\sim 6.5 \mathrm{yr}$ of MODIS Aqua observations over the New England region. There are several main findings from this analysis: (1) a direct comparison between coarse MYD04 $10 \mathrm{~km}$ AOD and high-resolution MAIAC $1 \mathrm{~km}$ AOD for all collocated AOD$\mathrm{PM}_{2.5}$ pairs for the same days and locations showed that both retrievals provide reasonable and similar correlations; (2) both retrievals indicate clear temporal variation in the association between AOD and $\mathrm{PM}_{2.5}$; (3) considering both clear and partly cloudy days, MAIAC provides on average a factor of 1.77 more retrievals at 85 EPA monitoring sites. The increase in data coverage has the potential to capture more days with greater spatial variability in $\mathrm{PM}_{2.5}$ as compared to $10 \mathrm{~km}$ MYD04, which should improve usefulness of AOD data to fill in the spatial pattern of $\mathrm{PM}_{2.5}$ for cells without monitoring stations; (4) analysis of MAIAC AOD$\mathrm{PM}_{2.5}$ collocated pairs for cloudy days when MYD04 provided no retrievals showed that while there is some reduction in MAIAC data quality, the total correlation coefficient and distribution of its daily values are relatively similar to their clear sky counterparts. This indicates that performance of MAIAC AOD retrievals remains quite reliable under partly cloudy conditions, and it can be used to increase the number of days for $\mathrm{PM}_{2.5}$ spatial pattern prediction based on satellite observations.

The results reported in this work were obtained by a straightforward analysis of the association between satellitebased atmospheric column AOD representing ambient conditions and near-surface $\mathrm{PM}_{2.5}$ measurements of dry particulate matter. This relationship is affected by a number of factors including vertical aerosol profile, meteorological conditions such as wind speed and humidity, aerosol chemical composition, and long-range aerosol transport. To some extent, the impact of these factors, in the absence of direct measurements, may be mitigated by the use of chemical transport models (e.g., Van Donkelaar et al., 2010; Liu et al., 2007). Other important factors include possible site sampling biases, for example caused by EPA site location (as discussed in Sect. 3.4), and also errors in $\mathrm{PM}_{2.5}$ measurements and uncertainties in AOD retrievals. Despite continuous improve- ments in aerosol retrievals since the year 2000 during the Earth Observing System era, there is still ample room for improvement. Some of the main errors are related to residual cloud and snow contamination, dependence on the land cover type for brighter, especially urban, surfaces, and lack of retrieval capability of aerosol microphysical properties from spectral-only MODIS measurements. In addition, none of the current algorithms addresses errors from side scattering of sunlight from clouds (3-D effects), which impact aerosol retrievals in cloudy environments (e.g., Wen et al., 2007). One clear outcome from this work is the need for quality assurance (QA) flags in MAIAC products to help users make the right choice for specific applications. Efforts toward this goal are currently underway.

There is a growing body of work aimed at improving the estimates of $\mathrm{PM}_{2.5}$ based on satellite-retrieved AOD using advanced statistical methods. Recently, several studies proposed that the effects of time-varying parameters influencing the AOD-PM ${ }_{2.5}$ relationship can be taken into account by using daily adjustments (Lee et al., 2011; Kloog et al., 2011; Chudnovsky et al., 2012). Kloog et al. (2011, 2012) introduced a day-specific calibration of AOD data using ground $\mathrm{PM}_{2.5}$ measurements and incorporated commonly used land use variables and meteorological parameters to produce much higher $R^{2}$ values than previously reported in the literature, ranging from 0.83 to 0.92 . The next step would be to apply a similar model to MAIAC data to investigate the spatial patterns of $\mathrm{PM}_{2.5}$ at high resolution, especially in urban areas where MAIAC data promise improvements.

Acknowledgements. This work was made possible by USEPA grant RD 83479801. Its contents are solely the responsibility of the grantee and do not necessarily represent the official views of USEPA. Further, USEPA does not endorse the purchase of any commercial products or services mentioned in the publication. The support for A. Lyapustin and Y. Wang is provided by the NASA Terra and Aqua Science Program. The authors greatly appreciate important comments of M. Wolfson and of the two anonymous reviewers.

Edited by: Y. Balkanski

\section{References}

Ackerman, S., Strabala, K., Menzel, W., Frey, R., Moeller, C., and Gumley, L.: Discriminating clear sky from clouds with MODIS, J. Geophys. Res., 103, 32141-32157, 1998.

Barnaba, F., Putaud, J. P., Gruening, C., dell'Acqua, A., and Dos Santos, S.: Annual cycle in co-located in situ, total-column, and height-resolved aerosol observations in the Po Valley (Italy): Implications for ground-level particulate matter mass concentration estimation from remote sensing, J. Geophys. Res., 115, D19209, doi:10.1029/2009JD013002, 2010. 
Bell, M., Ebisu, K., and Peng, R.: Community-level spatial heterogeneity of chemical constituent levels of fine particulates and implications for epidemiological research, J. Expo. Sci. Env. Epid., 21, 372-384, doi:10.1038/jes.2010.24, 2011.

Christopher, S. and Gupta, P.: Satellite Remote Sensing of Particulate Matter Air Quality: The Cloud-Cover Problem, J. Air Waste Manage., 60, 596-602, doi:10.3155/1047-3289.60.5.596, 2010.

Chudnovsky, A., Lee, H.-J., Kostinski, A., Kotlov, T., and Koutrakis, P.: Prediction of daily fine particulate matter concentrations using aerosol optical depth retrievals from the Geostationary Operational Environmental Satellite, J. Air Waste Manage., 62, 1022-1031, doi:10.1080/10962247.2012.695321, 2012.

Chudnovsky, A., Kostinski, A., Lyapustin, A., and Koutrakis, P.: Spatial scales of pollution from variable resolution satellite imaging, Environ. Pollut., 172, 131-138, 2013.

Emili, E., Popp, C., Pettita, M., Riffler, M., Wunderle, S., and Zebisch, M. $\mathrm{PM}_{10}$ remote sensing from geostationary SEVIRI and polar-orbiting MODIS sensors over the complex terrain of the European Alpine region, Remote Sens. Environ., 114, 11, doi:10.1016/j.rse.2010.05.024, 2010.

Emili, E., Lyapustin, A., Wang, Y., Popp, C., Korkin, S., and Zebisch, M.: High spatial resolution aerosol retrieval with MAIAC: Application to mountain regions, J. Geophys. Res., 116, D23211, doi:10.1029/2011JD016297, 2011.

Engel-Cox, J., Hoff, R., Rogers, R., Dimmick, F., Rush, A., and Szykman, J.: Integrating lidar and satellite optical depth with ambient monitoring for 3-dimensional particulate characterization, Atmos. Environ., 40, 8056-8067, 2006.

Estellés, V., Martínez-Lozano, J. A., Pey, J., Sicard, M., Querol, X., Esteve, A. R., Utrillas, M. P., Sorribas, M., Gangoiti, G., Alastuey, A., and Rocadenbosch, F.: Study of the correlation between columnar aerosol burden, suspended matter at ground and chemical components in a background $\mathrm{Eu}-$ ropean environment, J. Geophys. Res.-Atmos., 117, D04201, doi:10.1029/2011JD016356, 2012.

Gao, B.-C., Yang, P., Han, W., Li, R., and Wiscombe, W.: An algorithm using visible and $1.375 \mathrm{~mm}$ channels to retrieve cirrus cloud reflectances from aircraft and satellite data, IEEE Trans. Geosci. Remote, 40, 1659-1688, 2002.

Gupta, P. and Christopher, S. A.: Particulate matter air quality assessment using integrated surface, satellite, and meteorological products: Multiple regression approach, J. Geophys. Res., 114, D14205, doi:10.1029/2008JD011496, 2009a.

Gupta, P. and Christopher, S. A.: Particulate matter air quality assessment using integrated surface, satellite, and meteorological products: 2. A neural network approach, J. Geophys. Res., 114, D20205, doi:10.1029/2008JD011497, 2009b.

Gupta, P., Christopher, S., Wang, J., Gehrig, R., Lee, Y., and Kumar, N.: Satellite remote sensing of particulate matter and air quality assessment over global cities, Atmos. Environ., 40, 5880-5892, 2006.

Hilker, T., Lyapustin, A., Tucker, C., Sellers, P., Hall, F., and Wang, Y.: Remote Sensing of Tropical Ecosystems: Atmospheric Correction and Cloud Masking Matter, Rem. Sens. Environ., 127, 370-384, 2012.

Hoff, R. and Christopher, S.: Remote Sensing of Particulate Pollution from Space: Have We Reached the Promised Land?, J. Air Waste Manage., 59, 645-675, 2009.
Holben, B. N., Eck, T. F., Slutsker, I., Tanre, D., Buis, J. P., Setzer, A., Vermote, E., Reagan, J. A., Kaufman, Y. J., Nakajima, T., Lavenu, F., Jankowiak, I., and Smirnov, A.: AERONET - Afederated instrument network and data archive for aerosol characterization, Rem. Sens. Environ., 66, 1-16, 1998.

Kanabkaew, T.: Prediction of hourly particulate matter concentrations in Chiangmai, Thailand using MODIS aerosol optical depth and ground-based meteorological data, Environment Asia, 6, 6570, 2013.

Kaufman, Y. J., Tanre, D., Remer, L. A., Vermote, E. F., Chu, A., and Holben, B. N.: Operational remote sensing of tropospheric aerosol over land from EOS MODerate resolution imaging spectroradiometer, J. Geophys. Res., 102, 17051-17067, 1997.

Kloog, I., Koutrakis, P., Coull, B., Lee, H., and Schwartz, J.: Assessing temporally and spatially resolved $\mathrm{PM}_{2.5}$ exposures for epidemiological studies using satellite aerosol optical depth measurements, Atmos. Environ., 45, 6267-6275, 2011.

Kloog, I., Nordio, F., Coull, B. A., and Schwartz, J. D.: Incorporating local land use regression and satellite aerosol optical depth in a hybrid model of spatiotemporal $\mathrm{PM}_{2.5}$ exposures in the Mid-Atlantic states, Environ. Sci. Technol., 46, 11913e11921, doi:10.1021/es302673e, 2012.

Kumar, N., Foster, A., Chu, A., Peters, T., and Willis, R.: Satellite Remote Sensing for Developing Time-Space Resolved Estimates of Ambient Particulate in Cleveland, OH, Aerosol. Sci. Tech., 45, 1090-1108, doi:10.1080/02786826.2011.581256, 2011.

Lee, H. J., Liu, Y., Coull, B. A., Schwartz, J., and Koutrakis, P.: A novel calibration approach of MODIS AOD data to predict $\mathrm{PM}_{2.5}$ concentrations, Atmos. Chem. Phys., 11, 7991-8002, doi:10.5194/acp-11-7991-2011, 2011.

Levy, R. C., Remer, L. A., Mattoo, S., Vermote, E. F., and Kaufman, Y. J.: Second-generation operational algorithm: Retrieval of aerosol properties over land from inversion of Moderate Resolution Imaging Spectroradiometer spectral reflectance, J. Geophys. Res., 112, D13211, doi:10.1029/2006JD007811, 2007.

Levy, R. C., Remer, L. A., Kleidman, R. G., Mattoo, S., Ichoku, C., Kahn, R., and Eck, T. F.: Global evaluation of the Collection 5 MODIS dark-target aerosol products over land, Atmos. Chem. Phys., 10, 10399-10420, doi:10.5194/acp-10-10399-2010, 2010.

Levy, R. C., Mattoo, S., Munchak, L. A., Remer, L. A., Sayer, A. M., and Hsu, N. C.: The Collection 6 MODIS aerosol products over land and ocean, Atmos. Meas. Tech. Discuss., 6, 159-259, doi:10.5194/amtd-6-159-2013, 2013.

Li, R.-R., Kaufman, Y. J., Gao, B.-C., and Davis, C. O.: Remote sensing of suspended sediments and shallow coastal waters, IEEE Trans. Geosci. Remote, 41, 559-566, 2003.

Liu, Y., Kahn, R. A., Turquety, S., Yantosca, R. M., and Koutrakis, P.: Estimating fine particulate matter component concentrations and size distributions using satellite-retrieved fractional aerosol optical depth: Part 2 - A case study, J. Air Waste Manage., 57, 1360-1369, doi:10.3155/1047-3289.57.11.1360, 2007.

Liu, Y., Paciorek, C. J., and Koutrakis, P.: Estimating regional spatial and temporal variability of $\mathrm{PM}_{2.5}$ concentrations using satellite data, meteorology, and land use information, Environ. Health Persp., 117, 886-892, 2009.

Logue, J., Small, M., Stern, D., Maranche, J., and Robinson, A.: Spatial variation in ambient air toxics concentrations and health risks between industrial-influenced, urban, and rural sites, J. Air Waste Manage., 60, 271-286, 2010. 
Lyapustin, A., Wang, Y., and Frey, R.: An Automatic Cloud Mask Algorithm Based on Time Series of MODIS Measurements, J. Geophys. Res., 113, D16207, doi:10.1029/2007JD009641, 2008.

Lyapustin, A., Martonchik, J., Wang, Y., Laszlo, I., and Korkin, S.: Multi-Angle Implementation of Atmospheric Correction (MAIAC): Part 1. Radiative Transfer Basis and Look-Up Tables, J. Geophys. Res., 116, D03210, doi:10.1029/2010JD014985, 2011a.

Lyapustin, A., Wang, Y., Laszlo, I., Kahn, R., Korkin, S., Remer, L., Levy, R., and Reid, J. S.: Multi-Angle Implementation of Atmospheric Correction (MAIAC): Part 2. Aerosol Algorithm, J. Geophys. Res., 116, D03211, doi:10.1029/2010JD014986, 2011 b.

Lyapustin, A., Wang, Y., Laszlo, I., Hilker, T., Hall, F., Sellers, P., Tucker, J., and Korkin, S.: Multi-Angle Implementation of Atmospheric Correction for MODIS (MAIAC). 3: Atmospheric Correction, J. Rem. Sens. Environ., 127, 385-393, doi:10.1016/j.rse.2012.09.002, 2012a.

Lyapustin, A., Korkin, S., Wang, Y., Quayle, B., and Laszlo, I.: Discrimination of biomass burning smoke and clouds in MAIAC algorithm, Atmos. Chem. Phys., 12, 9679-9686, doi:10.5194/acp12-9679-2012, 2012b.

Martins, J. V., Tanre, D., Remer, L. A., Kaufman, Y. J., Mattoo, S., and Levy, R.: MODIS cloud screening for remote sensing of aerosol over oceans using spatial variability, Geophys. Res. Lett., 29, 1619, doi:10.1029/2001GL013252, 2002.

Munchak, L. A., Levy, R. C., Mattoo, S., Remer, L. A., Holben, B. N., Schafer, J. S., Hostetler, C. A., and Ferrare, R. A.: MODIS $3 \mathrm{~km}$ aerosol product: applications over land in an urban/suburban region, Atmos. Meas. Tech., 6, 1747-1759, doi:10.5194/amt-6-1747-2013, 2013.

Paciorek, C. J. and Liu, Y.: HEI Health Review Committee Assessment and statistical modeling of the relationship between remotely sensed aerosol optical depth and $\mathrm{PM}_{2.5}$ in the eastern United States, Research report (Health Effects Institute), 5-83, discussion 85-8391, 2012.

Paciorek, C. J., Liu, Y., Moreno-Macias, H., and Kondragunta, S.: Spatiotemporal associations between GOES aerosol optical depth retrievals and ground-level $\mathrm{PM}_{2.5}$, Environ. Sci. Technol., 42, 5800-5806, 2008.

Pelletier, B., Santer, R., and Vidot, J.: Retrieving of particulate matter from optical measurements: a semiparametric approach, J. Geophys. Res.-Atmos., 112, D06208, doi:10.1029/2005JD006737, 2007.

Remer, L. A., Kaufman, Y. J., Tanre, D., Mattoo, S., Chu, D. A., Martins, J. V., Li, R. R., Ichoku, C., Levy, R. C., Kleidman, R. G., Eck, T. F., Vermote, E., and Holben, B. N.: The MODIS aerosol algorithm, products, and validation, J. Atmos. Sci., 62, 947-973, 2005.
Remer, L. A., Mattoo, S., Levy, R. C., and Munchak, L. A.: MODIS $3 \mathrm{~km}$ aerosol product: algorithm and global perspective, Atmos. Meas. Tech., 6, 1829-1844, doi:10.5194/amt-6-1829-2013, 2013.

Schaap, M., Apituley, A., Timmermans, R. M. A., Koelemeijer, R. B. A., and de Leeuw, G.: Exploring the relation between aerosol optical depth and $\mathrm{PM}_{2.5}$ at Cabauw, the Netherlands, Atmos. Chem. Phys., 9, 909-925, doi:10.5194/acp-9-909-2009, 2009.

Tian, J. and Chen, D.: A Semi-Empirical Model for Predicting Hourly Ground-Level Fine Particulate Matter $\left(\mathrm{PM}_{2.5}\right)$ Concentration in Southern Ontario from Satellite Remote Sensing and Ground-Based Meteorological Measurements, Remote Sens. Environ., 114, 221-229, 2010.

Tsai, T.-C., Jeng, Y.-J., Chu, D. A., Chen, J.-P., and Chang, S.C.: Analysis of the relationship between MODIS aerosol optical depth and particulate matter from 2006 to 2008, Atmos. Environ., 45, 4777-4788, 2011.

Van Donkelaar, A., Martin, R. V., Brauer, M., Kahn, R., Levy, R., Verduzco, C., and Villeneuve, P. J.: Global estimates of ambient fine particulate matter concentrations from satellite-based aerosol optical depth: Development and application, Environ. Health Persp., 118, 847-855, 2010.

Van Donkelaar, A., Martin, R. V., Spurr, R. J. D., Drury, E., Remer, L. A., Levy, R. C., and Wang, J.: Optimal estimation for global ground-level fine particulate matter concentrations, J. Geophys. Res.-Atmos., 118, 5621-5636, 2013.

Wang, J. and Christopher, S. A.: Intercomparison between satellitederived aerosol optical thickness and $\mathrm{PM}_{2.5}$ mass: Implications for air quality studies, Geophys. Res. Lett., 30, 2095, doi:10.1029/2003GL018174, 2003.

Wen, G., Marshak, A., Cahalan, R. F., Remer, L. A., and Kleidman, R. G.: 3-D aerosol-cloud radiative interaction observed in collocated MODIS and ASTER images of cumulus cloud fields, J. Geophys. Res., 112, D13204, doi:10.1029/2006JD008267, 2007.

Wu, D., Lau, A. K.-H., Leung, Y., Bi, X., Li, F., Tan, H., Liao, B., and Chen, H.: Hazy weather formation and visibility deterioration resulted from fine particulate $\left(\mathrm{PM}_{2.5}\right)$ pollutions in Guangdong and Hong Kong, Huanjing Kexue Xuebao/Acta Scientiae Circumstantiae, 32, 2660-2669, 2012.

Zhang, H., Hoff, R. M., and Engel-Cox, J. A.: The Relation between MODIS Aerosol Optical Depth and $\mathrm{PM}_{2.5}$ over the United States: a Geographical Comparison by EPA Regions, J. Air Waste Manage., 59, 1358-1369, 2009.

Zhu, Y., Skuhn, M., and Hinds, W.: Comparison of Daytime and Nighttime Concentration Profiles and Size Distributions of Ultrafine Particles near a Major Highway, Environ. Sci. Technol., 40, 2531-2536, 2006. 